\title{
Design and Implementation of Soil Nutrient Monitoring System Based on "3S" Technology
}

\author{
Di $\mathrm{Zu}^{1,2,3}$, Zhongbin $\mathrm{Su}^{1^{*}}$, Xiaodong Yang ${ }^{2,3}$, Xiaohe $\mathrm{Gu}^{2,3}$ and Yancang Wang ${ }^{2,3,4}$ \\ ${ }^{1}$ School of Electronic Engineering and Information Northeast Agricultural \\ University, Harbin, 150030, China \\ ${ }^{2}$ Beijing Research Center for Information Technology in Agriculture \\ Beijing, 100097, China \\ ${ }^{3}$ National Engineering Research Center for Information Technology in \\ Agriculture, Beijing, 100097, China \\ ${ }^{4}$ Hebei Collaborative Innovation Center for Aerospace Remote Sensing \\ Information Processing and Application, Langfang, 065000, China \\ ${ }^{1}$ suzb001@163.com
}

\begin{abstract}
Soil nutrient monitoring system is to master the nutrient status of the bare ground, and quickly extract the information of farmland nutrient. Because of having a significant impact on the crop, the soil nutrient monitoring is important. For the lack of monitoring soil nutrient monitoring currently, combined with " $3 S$ " technology, spatial database technology, computer network technology and modern agricultural information technology as the basis, using WebGIS Service standard spatial database engine, the soil nutrient monitoring system based on soil nutrient information of Yangling was scientifically constructed. It achieved soil nutrient management from the large-scale, made the monitoring process towards standardization, improved management efficiency and scientific level, and provided technical support for farmland quality decisions.
\end{abstract}

Keywords: Soil nutrient; 3S; Monitoring system;

\section{Introduction}

Soil is the major means of production in agriculture, and one of the material basis of human survival. Soil nutrient is the main manure for plant growth, having a close relation with agricultural production. Therefore, finding out the dynamic changes of soil fertility and understanding the soil nutrient status become particularly important [1-3].

Traditional soil nutrient monitoring is sampling methods, that is, the sample unit under certain guarantee reliability was analyzed and processed [4]. Compared with traditional methods of soil nutrients experimental analysis, remote sensing technology is fast, nondestructive and largely obtain characteristic feature information. Hyperspectral remote sensing technology can get very narrow and continuous spectral data, and the spectral distribution of the soil can be obtained in real time. Multi-spectral sensors with high spatial resolution in the analysis of spatial patterns of soil nutrients with greater advantage. However, the data about the time, region, types and other important information was obtained by remote sensing instruments, just left by the way written monitoring reports, which was not conducive to research and reference for successor. So it is necessary to build a monitoring system on soil nutrient.

But there were more monitoring systems and warning systems designed on the quality of farmland dynamic changes. Land nutrient management put still emphasis up on regional management and infrastructure management, but dynamic monitoring and management lag behind, and there was also no single, large, fast and timely the system 
designed for farmland nutrient. Therefore, it is necessary to build a dynamic and real-time monitoring management system for soil nutrients, in order to timely and accurately grasp the changes of soil nutrients, to provide better decision support for the realization of national soil science management [5-7].

This article used the structural combine Browser/Server mode and Client/Server mode to develop soil nutrient monitoring system based on "3S" technology. The soil nutrient information was achieved by using the way RS and GPS and combined with the GIS functions, such as data analysis and processing, storage, management and distribution, to realize information support for soil nutrients. The system could monitor soil nutrients better and more accurate, which could realize the remote management for soil nutrient and provide intuitive, efficient and accurate information for users. What's more, it has scientific management decision support for the soil fast and largely [8].

\section{System Design}

\subsection{System Architecture Design}

Soil nutrient monitoring system was mainly service for agriculture-related research institutions and county, province and the country's agricultural management departments. The diversification of the service object required that the system must simple, friendly and easy to operate. The main structure of soil nutrient monitoring system had a $\mathrm{C} / \mathrm{S}$ version and a $\mathrm{B} / \mathrm{S}$ version. The system architecture is designed as a three-layer structure of the Web application, as shown in figure 1.

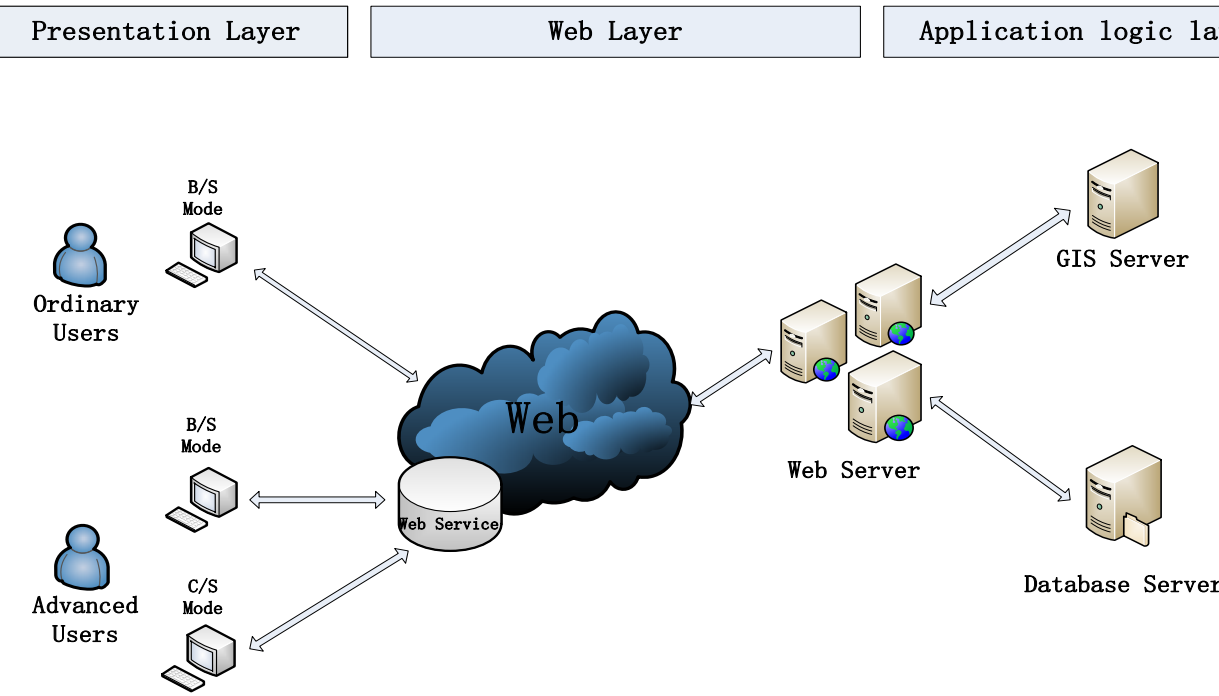

Figure 1. Framework Map of Soil Nutrient Monitoring System

Client layer was the browsing, business applications and processing interface, including the end-users and the system administrator. The browser using $\mathrm{B} / \mathrm{S}$ mode, is mainly applied to general users, which was designed to support the popular Internet Explorer 7.0 or higher, Firefox and Chrome and other common browsers. Manage client through combining $\mathrm{C} / \mathrm{S}$ mode with $\mathrm{B} / \mathrm{S}$ mode, was mainly for system administrators and advanced users.

Web tier was deployed on the Microsoft Internet Information Server (IIS). Web application server received a request from the client layer, which would be sent to the server, through the logic layer to be processing, responding and returning to the client. 
The application layer logically consisted of GIS servers and database servers. GIS servers and database servers were used to manage GIS data services and other data services, respectively. Then they responded to requests and sent results to the Web layer, and further sent to the client. The client achieved direct access to a service request through the Internet. The ESRI company's ArcGIS products and Microsoft SQL server were used as GIS servers and database servers, respectively.

\subsection{System Function Design}

The system mainly has the following functions, as shown in figure 2:

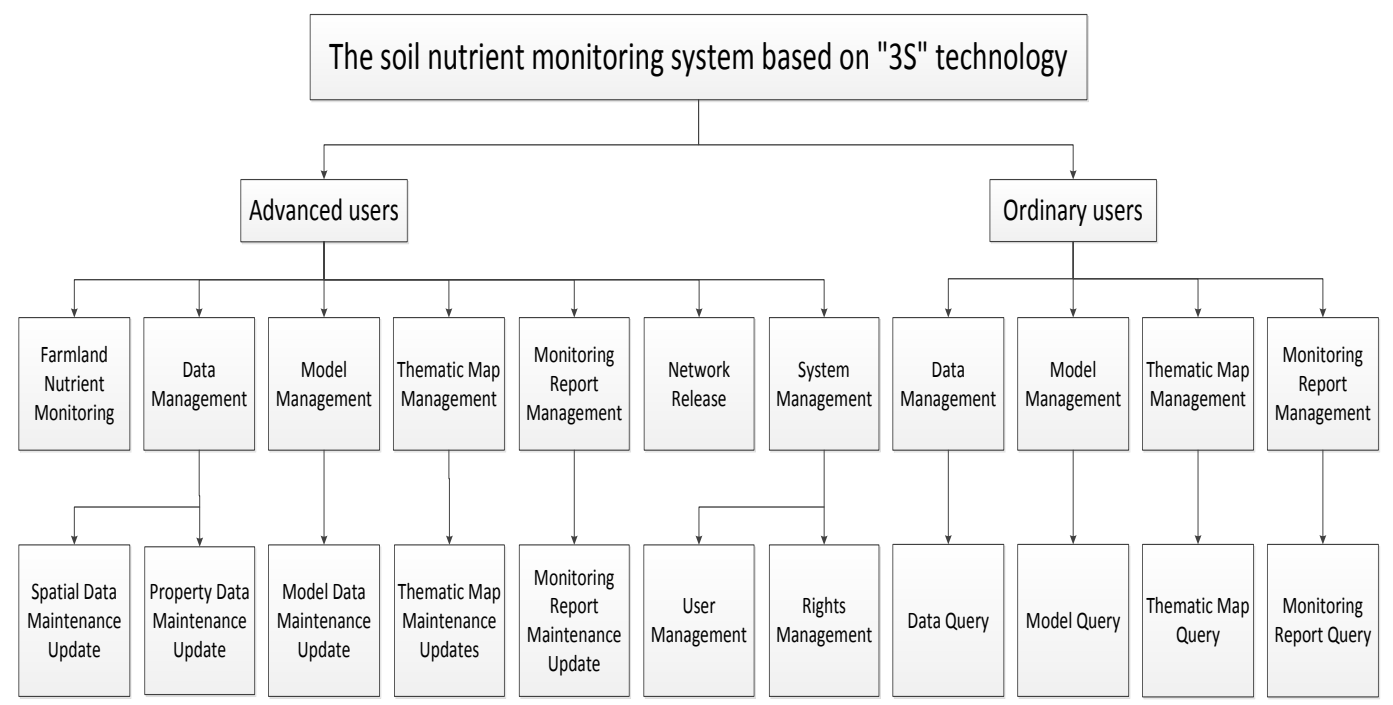

Figure 2. The Schematic Diagram of Farmland Nutrient System Functions

(1) System maintenance: Different users have different right to access and manage.

(2) System management : The management of users and user permissions.

(3) Data management: Pretreatment on the database of spatial data, images and vector data upload, browse, query and editing functions, and attribute data for data entry ,query and editing functions.

(4) Model management: Implementing the model query, delete function.

(5) Thematic map management: To achieve thematic map query, browse, delete and download functions.

(6) Monitoring report management: Implementing monitoring report query, browse, delete, and download capabilities. Then it provided users with accurate and intuitive visual expression, and provided a scientific basis and technical support for the various needs of macroeconomic policy-making departments.

(7) Network publishing: Implementing the publishing function of the data, thematic mapping and monitoring reports.

(8) Farmland nutrient monitoring: According to the screening criteria to later Chaturvedi and Figure Chavin way, the desired image data was determined, then a realistic model of monitoring and classification was created or selected, and finally the results were displayed and saved in the form of thematic mapping and monitoring reporting function. 


\subsection{System Database Design}

The system database included spatial database, attribute database, model database and text database. The spatial database used the way combine ArcSDE with SQL Server to manage and store. Attribute database, the model database and text databases directly used SQL Server for storage. The spatial database stored all kinds of raster data, including metadata, regional vector data, satellite remote sensing data and various image data appearing in the processing. The property database included the information from GPS monitoring and sampling point and soil testing data. The model database included the experienced model equations from various regions or different years by the different methods, and the model customized by advanced users. The text database included soil nutrients thematic maps, monitoring reports, user information, and other documentation data.

\section{System Implementation}

\subsection{Data sources and Preprocessing}

The system data included remote sensing data and ground monitoring stations data. For instance, Yangling Demonstration Zone in Shanxi Province SOM data in 2013 was obtained and handled. First, soil samples were collected by the way of five point mixing arable, which the sampling depth was $0-20 \mathrm{~cm}$. Then the samples were placed in the laboratory, dried, grinded and sieved (60 mesh) [9]. Soil organic matter was tested by the potassium dichromate volumetric method, which was described in Table1:

Table 1. Statistical Description of Soil Organic Matter Content

\begin{tabular}{lcccccc}
\hline Statistics & Quantity & Max & Min & Average & SD & Variance \\
\hline $\begin{array}{l}\text { Organic } \\
\text { Matter } \\
\%\end{array}$ & 30 个 & 3.19 & 1.29 & 1.85 & 0.42 & 0.17 \\
\hline
\end{tabular}

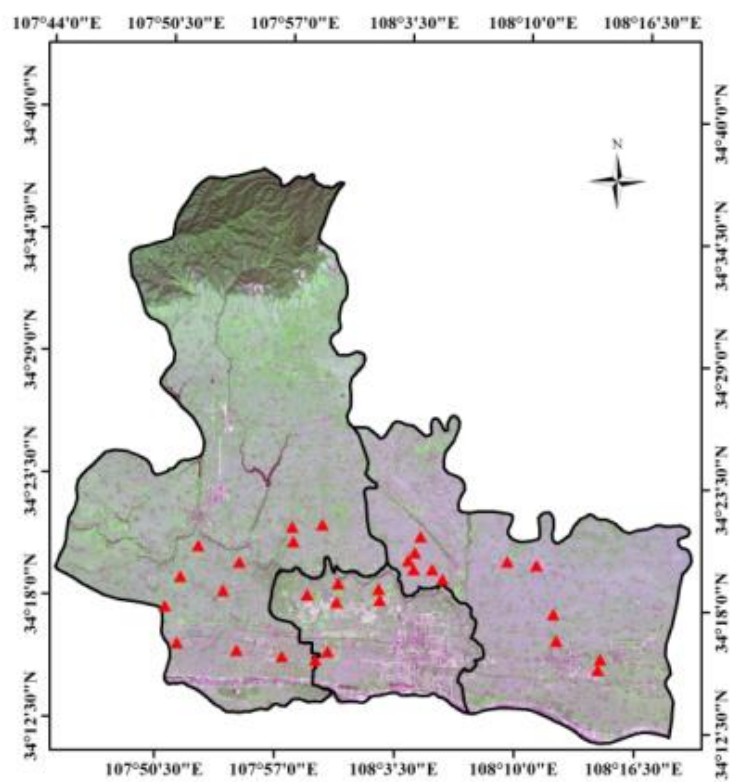

Figure 3. The Spatial Distribution Map of Soil Samples 
Second, the remote sensing image came from "Earth Observation and Digital Earth Science Center of Chinese Academy of Sciences - Earth Observation Data Sharing Program" to download the LandSat8 data on October 6, 2013, as shown in figure 4. The data sources are GEOTIFF format and Level 1 products.

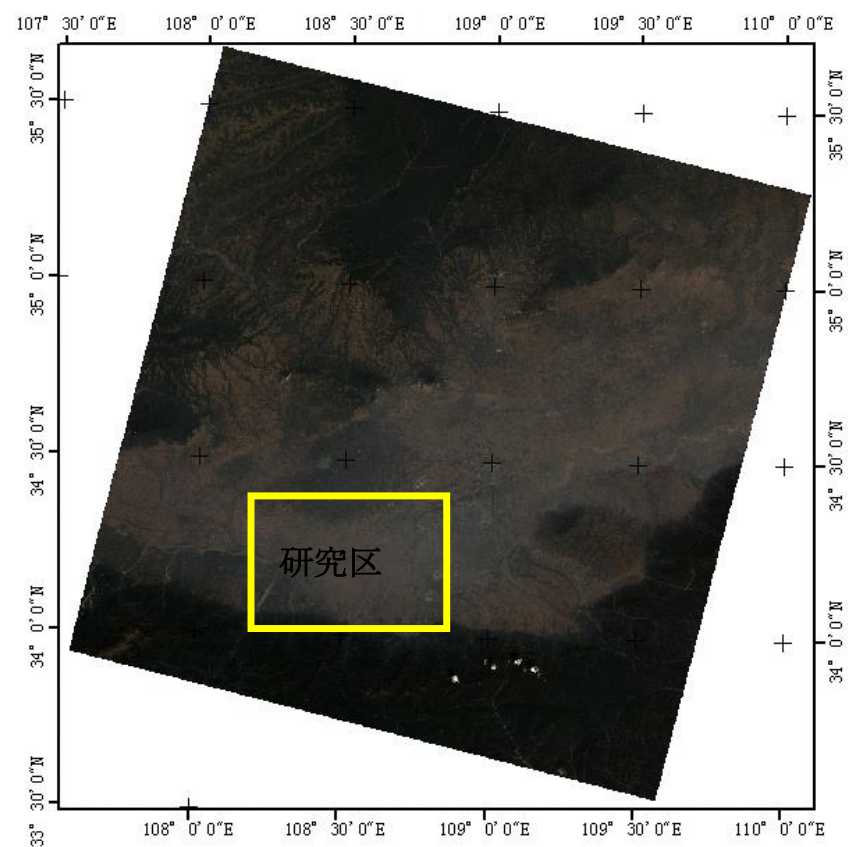

\section{Figure 4. The LandSat8 image in Shanxi Yangling Demonstration Zone}

Remote sensing image preprocessing is the premise and basis of quantitative inversion of surface parameters. General remote sensing image preprocessing includes radiometric and geometric correction, and radiometric correction can be divided into radiometric calibration and atmospheric correction. This study mainly used the ENVI 5.0 software platform to process remote sensing data.

\subsection{System Development Environment}

System servers used the Windows Server 2003 SP2 operating system, built .NET Framework platform, installed and configured ArcSED, SQL Server databases and ArcGIS Server. Ordinary users did not need to install any client software, just through the browser. Advanced users through the browser and exe executable file maintain the system.

Microsoft Visual Studio 2008 was used in the system development platform, Microsoft SQL Server 2008 was applied in the database system and three-tier model of ArcSDE was applied in the spatial data engine. Meanwhile, Asp.NET solutions and C \# language were used in the Server, the way combine C \# with JavaScript scripting language was put into use to develop in the client. Server-side and client-side debugging were conducted under Visual Studio.NET environment.

\subsection{System key Technologies}

\subsubsection{The Integrated Management of Multi-source Heterogeneous Data}

One important issue of data management is how to achieve integrated management of various types of data. Farmland nutrient monitoring systems need to collect information such as information of GPS monitoring sampling points, soil nutrient testing data, a 
variety of satellite remote sensing data, all of regional vector data, monitoring empirical model of soil nutrients and other basic information. Data sources, involving different information sources, include mathematical models, text data, vector data, remote sensing data, and so on. With the aid of advanced database technology, all the data were handed over to the GIS database and the database management system, and build libraries, store and manage, in order to improve the standard, security and efficiency of data .

\subsubsection{Monitoring Model}

Visible light and near infrared band spectrum information have certain correlation with soil organic matter content [10-11]. With this feature the people gave modeling analysis of soil nutrient by different methods. The regression equation was established by using CBERS-2 satellite to estimate soil total nitrogen (Shifeng Liu et al., 2010) [12]. The ground monitoring model of the organic matter content was constructed by using multiple linear regression analysis method (Xiangfeng Wang et al., 2014) [13]. The estimate model was established by using multiple stepwise linear regression and partial least-squares regression method (Lei Liu et al., 2011) [14].The estimate model for organic matter content was established by using stepwise multiple regression analysis (Juanjuan Zhang et al., 2011) [15]. The experienced model on soil nutrients was built by using partial least squares regression (Yongming Xu et al., 2006) [16].

This paper, taking the method (Wang Yancang et al., 2014) [17], used LandSat8 satellite images and ground soil data as the foundation. It made logarithmic transformation on multispectral bands and normalized soil index. Then Partial Least Squares was used to structure estimation models for each nutrient content. The process was shown in figure 5, and the results were shown in the table 2:

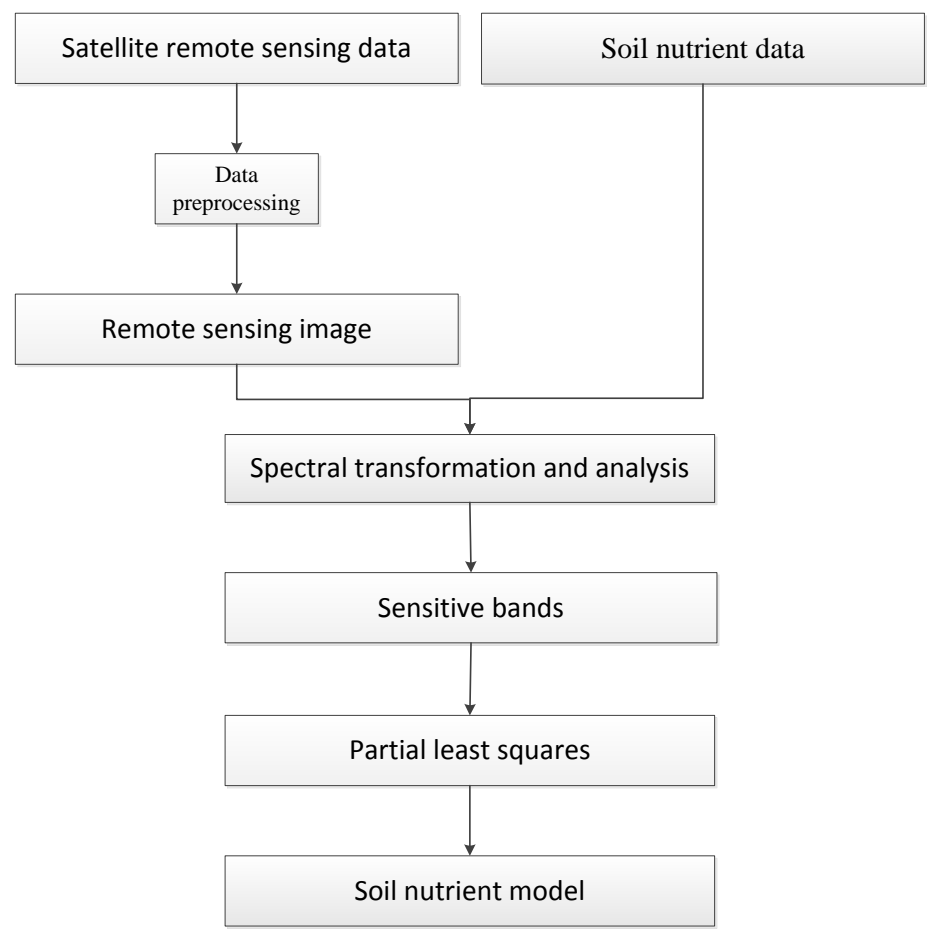

Figure 5. Flowchart of Model Establishment 
Table 2. Multispectral and Soil Nutrient Content of Partial Least Squares Regression Model Results

\begin{tabular}{|c|c|c|c|c|c|}
\hline \multirow[t]{2}{*}{$\begin{array}{c}\text { Soil } \\
\text { Nutrients } \\
\end{array}$} & \multirow[t]{2}{*}{ model } & \multicolumn{2}{|c|}{ modeling } & \multicolumn{2}{|c|}{ Verification } \\
\hline & & $\mathbf{R}$ & RMSE & $\mathbf{R}$ & RMSE \\
\hline $\begin{array}{l}\text { Organic } \\
\text { Matter } \\
(\%)\end{array}$ & $y=2.02+4.17 * b_{N D S I 4}+1.08 * b_{4}-6.71 * b_{5}+1.19 * b_{6}$ & 0.47 & 0.38 & 0.40 & 0.28 \\
\hline $\begin{array}{c}\text { Total } \\
\text { Nitrogen } \\
\text { (g/kg) }\end{array}$ & $y=-0.28-9.79 * b_{N D S I 7}+16.21 * b_{1}-20.98 * b_{4}+13.38 * b_{5}$ & 0.52 & 0.30 & 0.50 & 0.25 \\
\hline $\begin{array}{c}\text { Available } \\
\text { P } \\
(\mathbf{m g} / \mathbf{k g})\end{array}$ & $y=-365.94+699.41 * b_{N D S I 2}+4811.70 * b_{3}-2464.85 * b_{4}-688.52 * b_{6}$ & 0.61 & 14.96 & 0.34 & 22.67 \\
\hline $\begin{array}{c}\text { Available } \\
\mathbf{K} \\
(\mathbf{m g} / \mathbf{k g})\end{array}$ & $y=-639.8+1505.8 * b_{N D S I 1}-1424.4 * b_{N D S I 7}+22647.0 * b_{3}-17933.0 * b_{4}$ & 0.587 & 79.0 & 0.59 & 85.7 \\
\hline
\end{tabular}

From the above, although the soil nutrient monitoring model had a lot, these models were often subject to geographical, soil contaminants and different analytical methods. Monitoring models built on soil nutrients often was diverse, not fixed and sometimes in order to make the model more relevant, people often customized some elements such as $b_{N D S I 1}$, among $b_{N D S I 1}=\frac{b_{7}-b_{1}}{b_{7}+b_{1}}, b_{N D S I 2} 、 b_{N D S I 4} 、 b_{N D S I 7}$ and so on. These elements were defined by the spectral bands and spectral band was fixed. So if you could make sure capture images and videos, satellite monitoring model could be determined.

\section{System Application}

This farmland nutrient monitoring system achieved the digital and standardized management for information on soil properties and spatial information digitization. Each user had different permissions for data browsing, downloading, analysis and management capabilities. It was easy to get soil information, publish and manage. For example, the following will be soil organic matter of the nutrients in Yangling District. And the capacity as the senior administrator to mainly operate the Farmland nutrient monitoring module of the system.

First, the administrator ran the sensing image upload tool and namely uploaded remote sensing satellite images and vector graphics. After inputting the correct user name and URL in the browser and a password, the system was entered. The administrator could screen basic information, such as administrative regions, nutrient type and year to determine the satellite image data related information. The people could select the existing expertise models and classification standard, or the new models and classification customized for the actual situation customize. After determining the selected information, the system automatically generated the hierarchical distribution of thematic maps on soil nutrients in a designated boundary with vectors, as shown in figure 6 and figure 7. 


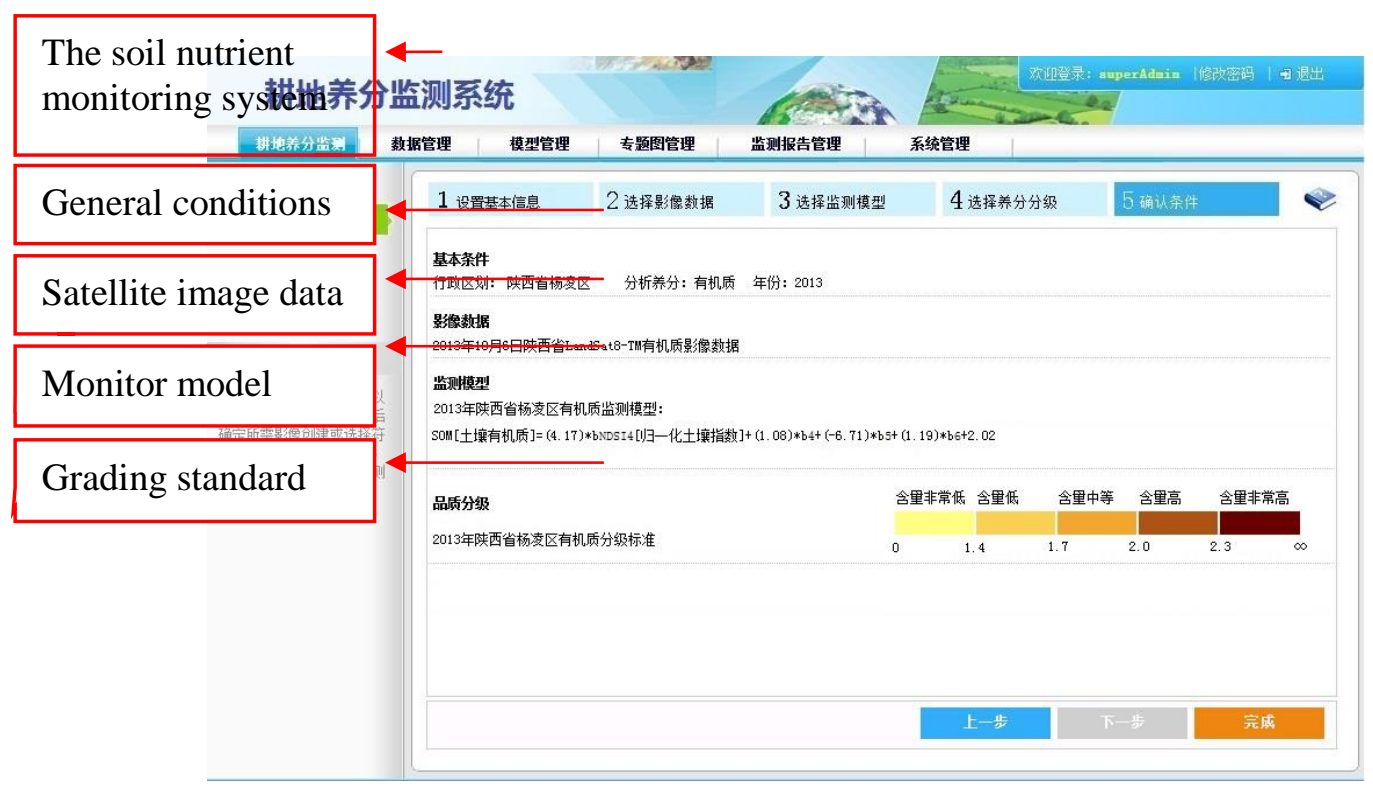

Fig. 6 The Interface of System

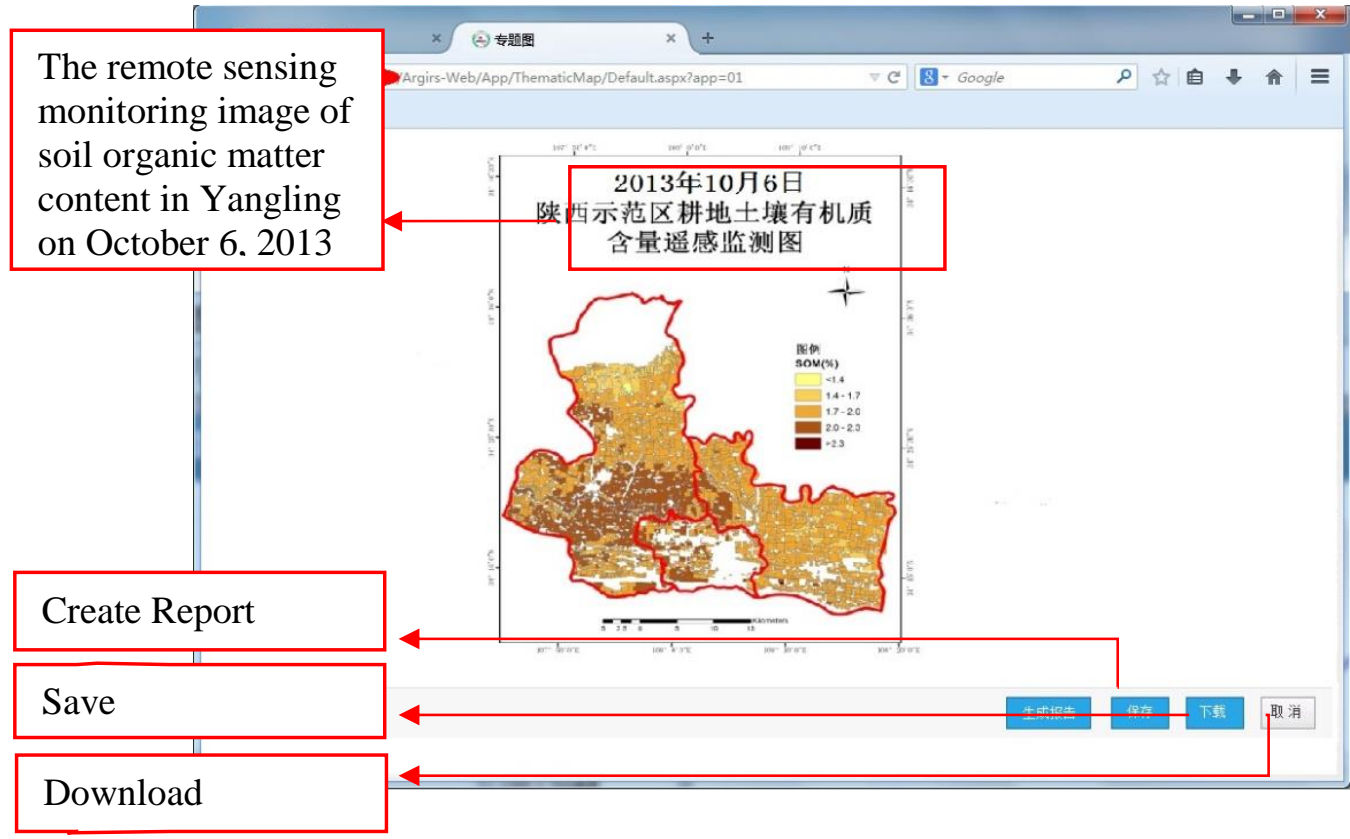

Fig. 7 The interface of Thematic Maps

In reality, the content of organic matter in the north and east of experimentation area was relatively low and homogeneous, and organic matter was relatively high in the southwest. The content of soil organic matter in northeastern block is located in the range of $1.2-2.0 \%$, while the content of the southwestern is located between $2.0 \%$ and $2.3 \%$. From the spatial distribution of soil organic matter content, as shown figure 7 , the organic matter content of soil nutrient in the research area is similar to the actual situation. Then the thematic map, meeting the requirements, was saved as a final monitoring report for users to download and use, as shown in figure 8: 


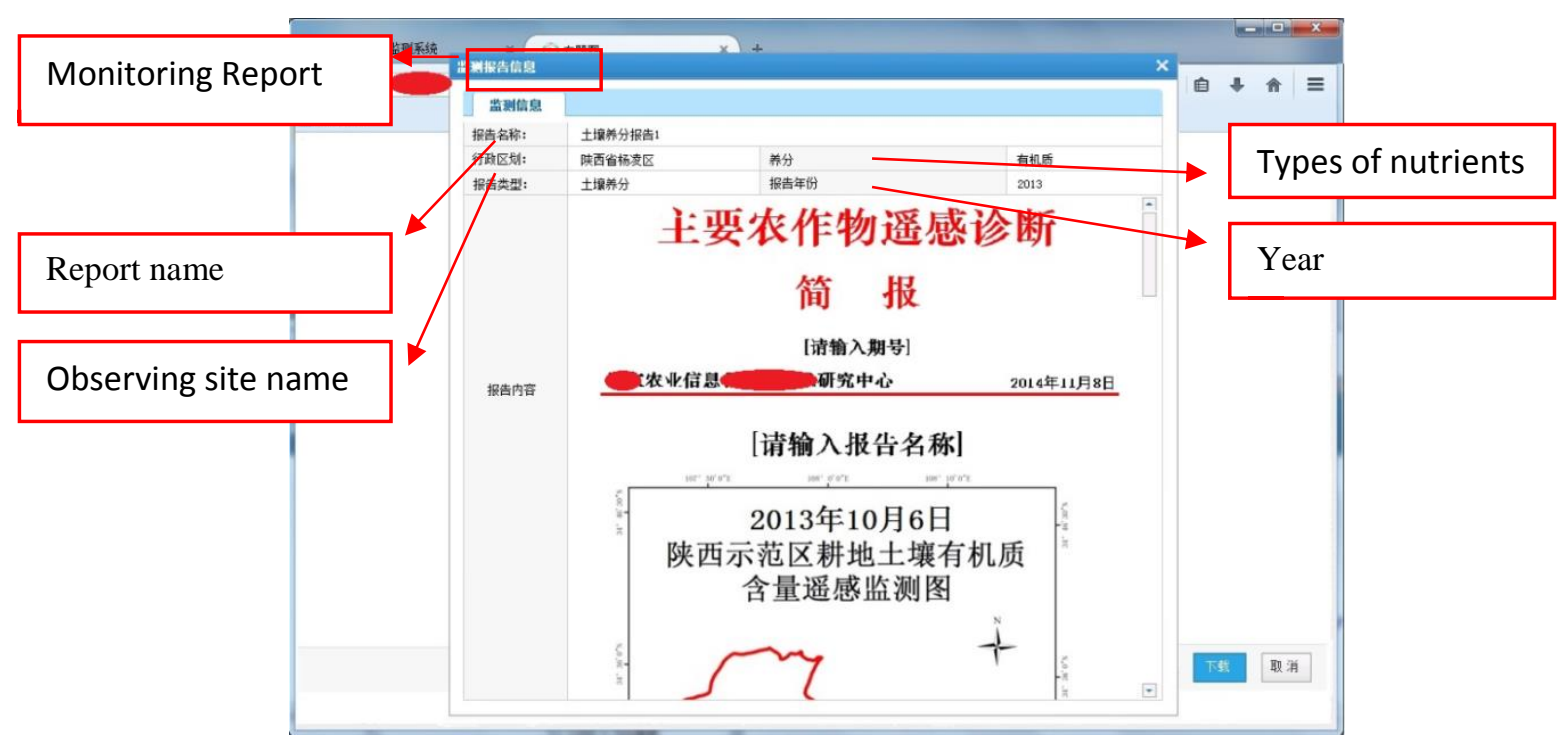

Fig. 8 The Interface of Monitoring Report

After being finished, the system was deployed and tested in Yangling Agricultural Hitech Industries Demonstration Zone Technology Information Center. The stability, flexibility and responsiveness of system met the requirements basic. In the aspect of function, the system initially met the users' demand for the farmland nutrient information. At present on the basis of the system, which is developing cultivated land productivity system and other systems about cultivated land environment and health quality. It will further enhance the scope and application quality of the system and provide scientific basis for precision agriculture.

\section{Conclusion}

With " 3 S" technology, spatial database technology, computer network technology and modern agricultural information technology as the basis, the system took the soil as the research object. It used WebGIS Service standard spatial database engine to build the soil nutrient monitoring system. Then it initially realized scientific and information management on the soil nutrients monitoring business, and further improved the level of the management and decision-making [18].

By using the data in Yangling, the system was tested and analyzed. The results showed that the design idea and architecture of system initially met the needs of precision agriculture, helped to make farmland data analysis, and made management become normalized and digitized [19]. Meanwhile, the system had the following characteristics.

1) The structure of system was designed combine $B / S$ with $C / S$. The system did not install the application in the client, gave full consideration for people accustomed to the operation interface design, and used unified interface style and simple operation.

2) This system fully considered the actual situation of national soil nutrients, used custom monitoring model and hierarchical way to make business analysis based on satellite images and ground data at different times in different regions, and built thematic maps and monitoring reports for a specific analysis of the problem. It increased application and scalability of the system to achieve practical results and dynamic monitoring of farmland nutrients.

3) The system combined RS technology with GPS technology and mixed satellite remote sensing image and data from actual measurement. The nutrient status of the arable land was monitored and the monitoring's precision and accuracy were improved. Then the system of data acquisition and monitoring functions were strengthen, at the same time, 
national and local farmland nutrient management level were also strengthen. It would be China's existing essential supplement and perfect part of monitor farmland.

This soil nutrient monitoring system is only a basic system. Its technical principles have some versatility, which can be applied to other information monitoring systems. On the one hand, this system will be added other farmland monitoring project, such as arable farmland productivity assessments system and environmental and health quality assessment system, to further expand the depth and breadth of the system. On the other hand, due to the continuity of arable data collection, the system will add the types of clients [20-21] and introduce portable terminals to combine the Internet technology with sensor technology. It will achieve scientific management of soil information collection, storage capabilities, and continuously improve the timeliness and usefulness of the system [22].

\section{Acknowledgements}

The authors are thankful to Mr ChunJiang Zhao and Guijun Yang for providing the graceful environment and support in writing programs. The work was supported by National High-tech R\&D Program of China (863 Program)(2013AA102303), National Natural Science Foundation of China (Grant No.41101395) and National Key Technology R\&D Program of the Ministry of Science and Technology (2012BAH29B04).

\section{References}

[1] H. N. Yan, "The status and evaluation of arable land in Pingdingshan City", vol. 18, no. 18, (2012).

[2] Q. Z. Wu, "The farmland nutrient status and utilization in Hainan province", vol. 27, no. 6, (2008).

[3] M. H. Chen, L. Xiao, W. Huang and G. M. Xue, "The Analysis of farmland nutrient status in Fuyang City", vol. 35, no. 4, (2010).

[4] Y. H. Shu,T. B. He, X. Gao,P. Y. Zhao, M. J. Pan, M. G. Zhao and E. X. Zhao, "The comprehensive evaluation of soil nutrients of cultivated land in mountainous county - Karst", vol. 37, no. 8, (2009).

[5] H. H. Liu, Z. Q. Hu, J. H. Zhou and F. X. Chen, "The farmland quality dynamic monitoring system in Guangdong Province", vol. 40, no. 35, (2013).

[6] Q. Zhang, W. J. Huang, T. Y. Xu, X. D. Yang and P. Sun, "Wheat growth of the seedlings remote monitoring and diagnosis system", vol. 27, no. 12, (2011).

[7] J. B. Yang, B. L. Hu and J. H. Ma, "The research on soil nutrients and soil conditions", (1995)

[8] H. Y. Yu, Y. M. Liu, Y. S. Dong, X. D. Yang, D. Ren and Q. Guan, "Crop growth of the seedlings monitoring system based on spatial information", vol. 34, no. 2, (2013).

[9] R. Kerry, M. A. Oliver and Z. L. Frogbrook, "Sampling in Precision agriculture", (2010).

[10] H. J. Liu, B. Zhang and D. W. Liu, "Black soil organic matter content prediction based on reflectance simulation models", vol. 28 , no. 12, (2008)

[11] H. J. Liu, X. Y. Zhang and S. F. Zheng, "Black soil organic matter predicting model based on field hyperspectral reflectance", vol. 30, no. 12, (2010).

[12] S. F. Liu, J. J. Pan, Z. Q. Yang, R. Q. Hu and S. Liu, "The research to estimate soil total N by using CBERS-2 satellite", vol. 1, (2010).

[13] X. F. Wang and J. H. Meng, "The farmland soil organic matter content monitoring based on HJ-1 satellite", vol. 30, no. 8, (2014).

[14] L. Liu, R. P. Shen and G. X. Ding, "Estimates based on soil organic matter content of hyperspectral", vol. 31, no. 3, (2011).

[15] J. J. Zhang, H. Yu, H. B. Qiao, X. M. Ma and Q. Y. Zhai, "The estimates of soil organic matter content based on high spectral characteristics", vol. 20, no. 5, (2012).

[16] Y. M. Xu, Q. Z. Lin, L. Wang and X. H. Huang, "The soil nutrients modelling based High-resolution reflectance spectra", (2006).

[17] Y. C. Wang, "The research on Inversion of soil organic matter content based multi-source remote sensing data quantification", (2014).

[18] L. B. Wang, "Agricultural Aid Decision Support System Based WebGIS Service”, vol. 13, no. 8, (2007).

[19] W. S. Guo, X. Yi, Y. P. Chen and X. Wang, "The soil spatial information management system based on WebGIS and bar code technology", vol. 9, (2010).

[20] J. V. Sinfield, D. Fagerman and O. Colic, "Evaluation of sensing technologies for on-the-go detection of macro-nutrients in cultivated soil", vol. 70, no. 1, (2010).

[21] V. I. Adamchuk, J. W. Hummel and M. T. Morgan, "On-the-go soil sensors for precision agriculture", vol. 44, no. 1, (2004) 
[22] Z. Liu, B. G. Li, M. Xu and Q. Gao, "The Design of County's Soil Information System Based on the open-source Web-GIS.30”, vol. 17, (2014).

\section{Authors}

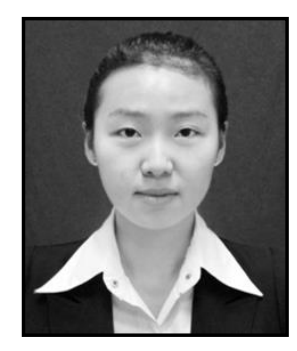

Di Zu (1991-), female, who is presently a under graduate student in Northeast Agricultural University. She got bachelor degree in software engineering in 2013. Her main research areas include WebGIS, 3S application in agriculture. 
International Journal of Smart Home

Vol. 9, No. 5 (2015) 